\title{
LA «ECONOMÍA ÉTNICA» COMO MOTOR PARA LA INTEGRACIÓN ECONÓMICA, JURÍDICA Y SOCIO-LABORAL DEL EMPRENDEDOR INMIGRANTE EN ESPAÑA Y EN LA UNIÓN EUROPEA
}

\author{
Ana Tomás López
}

doi: 10.18543/ed-64(2)-2016pp345-365

\begin{abstract}
SUMARIO: 1. INTRODUCCIÓN. 2. LA ECONOMÍA ÉTNICA COMO MOTOR PARA LA INTEGRACIÓN. 3. CONCEPTOS Y TEORÍAS: «EMPRENDEDOR ÉTNICO», «MINORÍAS INTERMEDIAS» Y «EMPRESARIOS DE ENCLAVE». 4. UNA APROXIMACIÓN A LAS CORRIENTES DOCTRINALES Y AL MARCO NORMATIVO DEL NEGOCIO ÉTNICO EN ESPAÑA Y EN LA UE. 5. LA CONSTITUCIÓN ECONÓMICA EN LA ENCRUCIJADA. 6. CONCLUSIONES. VII. REFERENCIAS BIBLIOGRÁFICAS.
\end{abstract}

\section{INTRODUCCIÓN}

La economía étnica se ha convertido en un nuevo campo de investigación en el marco de las relaciones económicas, creando nuevos paradigmas en torno a las denominadas "Constituciones económicas», en especial a partir de los años setenta. Lo cual ha suscitado un intenso debate científico sobre los diversos modos de incorporación laboral de los inmigrados en las sociedades de instalación, como resultado de la proliferación de empresas regentadas por inmigrantes o minorías étnicas en las últimas décadas. Planteando -sin duda-nuevas fórmulas para la integración económica, jurídica y social de los inmigrantes en España y en la Unión Europea (en adelante UE), y 
superando la supuesta temporalidad o vinculación cuasi-exclusiva al modelo norteamericano forjado a lo largo del siglo $\mathrm{XX}^{1}$.

Por ello, este fenómeno -especialmente motivado por el impacto financiero y socio-laboral que produce en los lugares donde se origina- suscita un creciente interés económico y académico. No obstante, y debido a su enorme complejidad, las teorías, los conceptos y las interpretaciones jurídicas y jurisprudenciales desarrollados son dispares y, hasta cierto punto, contradictorios, creando un enfoque descriptivo o interpretativo multicausal, que motiva la necesidad y relevancia de ser dilucidado a través de presentes y futuras investigaciones.

De este modo, los procesos socio-económicos se convierten en un factor crucial para la innovación y la transformación de las Constituciones económicas, tanto como agente activo de las mismas como vehículo de los valores, modelos de comportamiento, evolución y adaptación que el cambio tecnológico y la $\mathrm{I}+\mathrm{D}+\mathrm{i}$ conllevan, y como tales emergen como ámbito de investigación transversal a todos los retos de la sociedad. Entre ellos, podemos encontrar el tema de estudio propuesto: la iniciativa económica del extranjero como derecho fundamental y mecanismo de integración en España y en la UE. La cual consideramos una manifestación directa del impacto económico, social y cultural de los flujos migratorios y de la relación de la Administración con empresas y ciudadanos, como nuevo paradigma de integración socio-laboral; así como un fenómeno de transformación económica y social de trascendental calado, que se configura como un importante desafío para la sociedad española. De ahí deriva la importancia de promover su estudio, como modelo de contribución al desarrollo social y económico de nuestros territorios (en especial a nivel local y regional), planteando un análisis que contemple tanto las implicaciones económicas, como sociales de este nuevo comportamiento, sin perder de vista el estatuto jurídico de la persona extranjera.

\section{LA ECONOMÍA ÉTNICA COMO MOTOR PARA LA INTEGRACIÓN}

De esta forma, la economía étnica, pese a ser un fenómeno antiguo, adquiere hoy renovado interés y relevancia, en virtud de las actuales transformaciones económicas y demográficas, a nivel nacional, europeo e internacional.

1 Arjona Garrido, A. y Checa Olmos, J. C., «Economía étnica. Teorías, conceptos y nuevos avances», Revista Internacional de Sociología (IRIS) LXVI, núm. 45 (Septiembre-Diciembre, 2006): 118. 
Enmarcado en la Constitución económica, el concepto «trabajo» constituye «la piedra angular de la estructura estatal $»^{2}$, entendido éste en sentido unitario y gracias a un importante «proceso de mutación genética» tras la ruptura del pacto fordista ${ }^{3}$. Además, avala una interpretación más amplia que defiende que el sujeto realiza una función que trasciende el mero posicionamiento social, al sumarse a un proyecto con una finalidad general reflejada en la Constitución económica como un progreso material o espiritual de la sociedad en su conjunto. De esta forma, en relación al extranjero, si aceptamos esta visión antropológica e individualista de la norma fundamental, el deber de desarrollar una actividad útil para la sociedad terminaría por compartir la misma esencia funcional de la integración de la persona en el Estado nacional y en la propia sociedad. Por lo tanto, a través de esta comunicación no podemos dejar de analizar todas aquellas situaciones dicotómicas que, de forma breve, podríamos definir como oportunidades o desventajas y que, en definitiva son responsables de la oscilación entre el estatus jurídico y material del trabajador inmigrante, por cuenta propia o ajena.

Por ello, y como se ha avanzado, pretendemos trascender el estudio de las iniciativas empresariales estrictamente comerciales de los inmigrantes para contemplarlos individualmente como personas o sujetos de derecho. $\mathrm{O}$, lo que es lo mismo, como entes merecedores de ser titulares de deberes y derechos en nuestra nación y en el marco comunitario. Con este fin, nos aproximamos a los empresarios de origen inmigrante teniendo en cuenta la creciente heterogeneidad interna del colectivo y el amplio espectro de actividades empresariales que realizan. A pesar de que muchas de las iniciativas emprendedoras de los migrantes tienen lugar en el ámbito de las microempresas y en el comercio, son cada vez más habituales otros tipos de actividades empresariales como organizaciones no gubernamentales, agencias de cooperación internacional, asociaciones culturales, espacios educativos, medios de comunicación social, empresas de servicios domiciliarios, empresas de reformas y construcción o profesionales liberales como odontólogos, gabinetes jurídicos, etc. ${ }^{4}$.

De esta forma, nuestro estudio se aproxima a los negocios regentados por personas inmigradas, procedentes de países no comunitarios, asumiendo que hablamos de «inmigrante» no sólo como categoría jurídica, sino también social.

2 Olivetti, M., Articolo 1, en Bifulco, R., Celotto, A. y Olivetti, M. (coords.), Commentario alla Costituzione, Vol. I (art. 1-54) (Torino: Utet, 2006), 5.

${ }^{3}$ LASA LóPez, A., Constitución económica y derecho al trabajo en la Unión Europea, (Grandad: Editorial Comares, 2011), XVII-XVIII.

${ }^{4}$ Solé, C. y S. Parella, S., Negocios étnicos. Los comercios de los inmigrantes no comunitarios en Cataluña (Barcelona: CIDOB, 2005), 16 y ss. 
Paralela y habitualmente, el estudio cuantitativo de los flujos migratorios en España se realiza a partir del concepto de extranjería -no de inmigración-, y de la variable nacionalidad. Así lo establecen los registros estadísticos oficiales. Sin embargo, partimos de la premisa que la categoría «extranjero/a», de carácter administrativo y jurídico, es insuficiente cuando se aborda la inmigración como fenómeno económico y social. El concepto «inmigrante» remite a personas que han emigrado por motivos diversos, habitualmente económicos, procedentes de países en vías de desarrollo. Generalmente esta etiqueta se aplica a las personas originarias de países considerados menos desarrollados en el orden económico internacional, con independencia de si han adquirido o no la nacionalidad española. Por todo ello, nos referimos a los negocios regentados por personas inmigradas, en sentido amplio, teniendo en cuenta su lugar de procedencia, sea cual sea su situación jurídica. Base argumental sobre la cual se podrían plantear diversos niveles de análisis.

El primero de ellos, en torno a la aproximación al empresariado de origen inmigrante como sujeto de derechos y obligaciones, buscando dar respuesta a posibles interrogantes como los siguientes: ¿el ordenamiento jurídico español con carácter general- y la Constitución económica -de forma específica- proveen los mecanismos jurídicos necesarios para promover y lograr la plena integración económica, laboral y social del empresario «étnico»? ¿Son suficientes y eficaces las políticas públicas creadas con este fin? ¿Cuáles son los principales mecanismos de garantía y tutela de sus derechos? ¿Y para el control económico y social? ¿Son realmente efectivos? ¿Sucede lo mismo en el marco comparado, en relación al ordenamiento jurídico comunitario e internacional?

Un segundo nivel debería tener en cuenta al emprendedor inmigrante como actor individual, despejando diversas hipótesis de estudio. Por ejemplo: ¿qué les impulsa a crear sus propios negocios?, Y, en torno a los factores diferenciales, ¿cuáles son las principales diferencias entre el emprendimiento «étnico» y el nacional? ¿Podemos considerarlos «empresarios innovadores», o más bien empresarios que establecen negocios fruto de la «necesidad»? ¿Están creando nuevos paradigmas o patrones en materia de emprendedurismo y generación de riqueza en nuestro país?

En tercer lugar, también sería necesario detenerse en el estudio del capital social de estos empresarios, de los «recursos étnicos» utilizados, ya que no son agentes que operen en el vacío social, sino integrados en redes sociales. Y mucho más hacerlo desde un marco comparado en torno al estatus jurídico, laboral y social de los empresarios «étnicos» en sus diferentes niveles territoriales.

Un cuarto nivel podría plantear la relación y los vínculos entre las iniciativas empresariales de los inmigrantes y la transformación de la estructura económica urbana, unido al impacto de la implementación de políticas municipales, provinciales, regionales, nacionales, europeas e internacionales creadas ad hoc. 
Para finalizar, debido a la trascendencia y complejidad del tema que nos ocupa, una investigación en torno a la economía étnica se debería desarrollar sobre un marco metodológico multidisciplinar, con el análisis de documentos y actos jurídicos, a través de su interpretación jurídica y jurisprudencial y con el procesamiento de datos cuantitativos y cualitativos. Para finalizar, y como trasfondo, sería relevante hacerse eco del debate y los retos sociales generados en el ámbito de la ciudadanía española y europea, no desde un mero punto de vista descriptivo, sino científico. Partiendo de una crítica más constructiva que tienda a la edificación de puentes sólidos que posibiliten una auténtica integración del emprendedor «étnico» como fuente de prosperidad y riqueza para nuestro país, creando de esta forma nuevos paradigmas o modelos sociales de cohesión económica y social.

No obstante, somos plenamente conscientes de que este planteamiento científico es realmente ambicioso y que, por su propia naturaleza se excede a los límites lógicos de la presente comunicación. Por ello, y centrándonos en unos objetivos realistas para el actual trabajo, -que es más cercana a una aproximación teórico-conceptual-, en primer lugar analizaremos el marco teórico-jurídico del cual partimos para comprender mejor en qué consiste la economía étnica y cuál es su verdadero impacto a todos los niveles -en especial jurídico, económico, social y laboral- en nuestro país y en la UE.

\section{CONCEPTOS Y TEORÍAS: «EMPRENDEDOR ÉTNICO», «MINORÍAS INTERMEDIAS»Y «EMPRESARIOS DE ENCLAVE»}

La UE no es ajena a la corriente xenófoba y las controversias que se han suscitado en torno a los trabajadores inmigrantes, en especial, el trabajador extranjero no comunitario. Desafortunadamente, constituye una tendencia creciente conocida bajo el término «antagonismo étnico», acuñada en la década de los setenta y ampliamente estudiada por diversos autores, entre los que destaca BONACICH. Ha abarcado todos los niveles de conflicto intergrupales, desde sus ideologías y creencias -tales como el racismo y el prejuicio-, pasando por sus diversos comportamientos -discriminación, disturbios o agresiones físicas y psicológicas-, hasta llegar a las propias instituciones -a través de las leyes que perpetúan la segregación-. De hecho, en muchos contextos sociales, se sigue proyectando una imagen negativa del trabajador extranjero, al estar asociada frecuentemente a la figura del pequeño comerciante, el mercader, el tendero de barrio, el vendedor ambulante, e incluso a la del maleante, el traficante o el trabajador clandestino.

Sin embargo, es en fechas recientes cuando se empieza a contemplar la iniciativa empresarial étnica como un fenómeno social, que invita a desarrollar, cuestionar y revisar muchos conceptos y teorías del espíritu empresarial étnico para proporcionar una explicación más amplia, positiva y realista del 
mismo. No en vano, se ha demostrado que ciertos grupos de inmigrantes o minorías étnicas tienen mayor iniciativa empresarial y mayor probabilidad que otros de adoptar la propiedad de pequeños negocios como una de las estrategias más efectivas en su búsqueda de movilidad socioeconómica ${ }^{5}$, transformando el concepto clásico de «minorías intermedias» o middleman minorities ${ }^{6}$. De esta forma, cada vez es más frecuente comprobar que los emprendedores étnicos abren negocios en barrios urbanos con recursos y en suburbios de clase media, emergiendo no sólo en el sector secundario, sino también en el sector primario de la economía dominante de la sociedad de destino. Incluso sin apenas llegar a establecer lazos con las estructuras y relaciones sociales de la comunidad local en la que realizan sus actividades económicas, al contrario que los denominados «empresarios de enclave» ${ }^{7}$; aunque ambos conceptos -«minorías intermedias» y «empresarios de enclave»-, cada vez aparecen más cercanos y desdibujados, pudiendo el emprendedor extranjero llegar a desempeñar ambos roles. Por otro lado, es lógico si tenemos en cuenta que los enclaves étnicos evolucionan para convertirse en barrios multiétnicos, al mismo tiempo que se desarrollan nuevas concentraciones en los suburbios de clase media con mayores recursos. Lo principal es que este salto cualitativo genera fórmulas que permite a estos empresarios subir puestos en la escala social y mejorar sus ingresos. Lo cual terminará repercutiendo en el crecimiento general de la economía nacional y europea. Todos éstos son algunos de los efectos de la denominada «economía étnica», cuyo concepto comenzaremos a desentrañar a continuación.

5 Glazer, N. y Moynihan, D.P., Beyond the Melting Pot (Cambridge: MIT Press y Harvard University Press, 1963), 290-291.

${ }^{6}$ Según Bonacich, las minorías intermediarias están constituidas por aquellos empresarios que realizan intercambios entre la élite de una sociedad y las masas. Históricamente, eran personas que permanecían poco tiempo en un lugar, interesadas en obtener un rápido margen de ganancia de sus negocios portátiles y fugaces para reinvertir luego su dinero en otra parte, incluyendo con frecuencia un retorno a su hogar. Tradicionalmente, solían establecer nichos de negocio en barrios pobres o en ghettos de inmigrantes en áreas urbanas, abandonadas por las industrias, empresarios y servicios dominantes de venta al por menor. Véase BonACich, E., «A Theory of Middleman Minorities», American Sociological Review 38 (1973), 583-594.

${ }^{7}$ Los «empresarios de enclave», en contrapartida, incluyen principalmente a quienes están ligados por una etnicidad compartida, estructuras sociales de la misma etnia y ubicación. En sus inicios, operaban negocios en barrios de inmigrantes en los que sus compañeros de grupo étnico eran dominantes y entretejían un intrincado sistema de redes sociales entre personas del mismo grupo étnico, dentro de un enclave autosuficiente. Véase ZHOU, M., «Una recapitulación del espíritu empresarial de los grupos étnicos: Convergencias, controversias y avances conceptuales», en PoRTES, A. y DE WIND, J. (eds.), Repensando las migraciones: Nuevas perspectivas teóricas yempíricas (México: Universidad Autónoma de Zacatecas, 2006), 233. 
Los primeros autores en desarrollar el concepto de «economía étnica» fueron LIGHT (1972), BONACICH y MODELL (1980). Para su diseño, partieron de la clara diferenciación entre el empleo que se genera dentro de la economía general y el que las minorías empresarias crean para sí mismas. La base es un mercado de trabajo dividido, determinado por el antagonismo étnico y que, como resultado final, ocasiona la aparición de las minorías étnicas como primer eslabón de la economía étnica. Al incluir a cualquier persona inmigrante que sea empleador, auto-empleador o que esté empleado en empresas coétnicas, se crea un tipo de economía definido por raza, etnicidad u origen nacional. Éste se caracteriza por alcanzar ventajas en las relaciones entre propietarios de negocios y entre propietarios y trabajadores del mismo origen nacional ${ }^{8}$.

Posteriormente, han surgido estudios muy interesantes en los que se analizan, en mayor medida, la independencia económica de los inmigrados y de los grupos étnicos, y no únicamente de las minorías intermediarias. Entre otros, cabe destacar los de YEUNG (1999), KIM (1999, 2003) y LEE, (2002) $\mathrm{y}$, de forma muy especial, los de MIN (desde 1992). Todos ellos se engloban en la teoría de las middleman minorities, superando la corriente estrictamente culturalista, pero incorporando elementos propios de la aproximación interactiva. En ellos, se afirma que los empresarios étnicos tienen como nexo común la búsqueda de estrategias para escapar de la exclusión social y económica a la que estaban sometidos, en el sentido de que -como bien señala LIGHT «la independencia económica, parcial o total, representa para los inmigrados y las minorías étnicas una autodefensa básica frente a la exclusión y las desventajas que tienen en el conjunto del mercado laboral. Esto les permite superar esas desventajas y ellos mismos pueden negociar los términos de su participación en el mercado de trabajo desde una cierta posición de fuerza ${ }^{9}$. Todo ello, compartiendo las tesis de ARJONA y CHECA (2006), nos lleva a dos conclusiones básicas. La primera: que la economía étnica funciona como mercado de trabajo interno $\mathrm{y}$, en muchas ocasiones, como «escuela de emprendedores» ${ }^{10}$. La segunda: que ésta genera economías interétnicas que compiten con los mercados autóctonos abiertos ${ }^{11}$.

${ }^{8}$ Logan, Alba y McNulty, cit., 1994, 698.

9 Light, cit., 2003, 1.

${ }^{10}$ Coincidiendo con Arjona y Checa, con esta nueva percepción se pone de relieve que la economía étnica funciona, asimismo, como mercado de trabajo interno. Su propio funcionamiento permite a los trabajadores coétnicos asalariados montar su propio negocio. El objetivo es proteger a los inmigrados de la competencia del mercado de trabajo general. Es por ello por lo que en momentos de recesión de la economía general donde no se demanda mano de obra, se siguen manteniendo los flujos migratorios de colectivos que emplean en la economía étnica. Vid. ArJona Garrido, A. y CheCa Olmos, J. C., cit., 127 y 128.

${ }^{11}$ De forma paralela, cuando se genera una independencia total del mercado general, provoca que los empresarios pertenecientes al mismo gremio, pero de distintos orígenes 
Como resultado, esta nueva concepción de economía étnica abre principalmente dos vías de análisis en el plano doctrinal de la Constitución económica $^{12}$. Por un lado, la movilidad laboral y social entre los miembros del grupo, como aquella que genera las oportunidades entre empleados y empleadores. Por otro, las variaciones en el nivel de integración económica, bien de los inmigrados que se incorporan a la economía general a través del empleo coétnico, bien de las minorías étnicas en contextos sociales diferentes ${ }^{13}$.

Sin embargo, pese a los grandes avances teóricos que se han producido en estas últimas décadas, todavía resta por resolver bastantes incógnitas en torno a otros conceptos que se derivan del empresariado étnico. Por ejemplo, las condiciones necesarias para que emerja un enclave, los costes y beneficios de trabajar en este tipo de empresas, el tamaño de las mismas, los servicios y productos ofertados, los clientes, la dimensión comercial o si el mercado de trabajo étnico presenta características y propiedades del mercado primario, secundario o bien son propias. Lagunas que, necesariamente, deberán ser abordadas con profundidad en futuros estudios, dado que afectan directamente a la lógica económica, social, cultural y espacial del fenómeno de la economía étnica.

Estos hechos son trasladables a la realidad española. No obstante, si bien en la última década han proliferado de forma muy notable los estudios y las investigaciones, éstos se han centrado en áreas geográficas muy concretas; así como en el abordaje de las minorías intermediarias y los empresarios de enclave. Las primeras se ubican fundamentalmente en barrios de inmigrantes. En ellas tienen cabida incluso los profesionales liberales -como por ejemplo médicos o abogados-, y los empresarios dedicados a actividades con una clientela mayoritaria no coétnica, como son la artesanía, la venta ambulante o los restaurantes chinos o argentinos. El siguiente tipo son empresarios de enclave. Destacan los musulmanes en carnicerías halal (en especial, marroquíes y pakistaníes en Barcelona y Madrid; o marroquíes y argelinos en Almería). Respecto a la clasificación que distingue entre propiedad y control, la propiedad es más frecuente entre los emprendedores dedicados a negocios de alimentación, venta ambulante, restauración y artesanía. Por su parte, el control étnico se ejerce en las empresas de telefonía y envío de dinero, ya que la titularidad pertenece a grandes empresas multinacionales, como

\footnotetext{
-judíos, japoneses o chinos, entre otros- se interconecten, creando economías interétnicas que compiten con los mercados autóctonos abiertos. Ibidem, p. 128.

${ }^{12}$ Ibidem, p. 128.

13 Light, I. y Karageorgis, S., "The ethnic economy», en Smelser, N. y SwedenBERG, R. (edit.), The handbook of economic sociology (Nueva York: Russell Sage Foundations, 1994), 648 y ss.
} 
Telefónica, Money Gram o Western Union. En cualquier caso, -como destacan SOLÉ y PARELLA (2005)- es importante resaltar que, pese a algunas excepciones, la normalidad administrativa y jurídica rige en estos negocios.

No obstante, finalmente, deberíamos preguntarnos si en España estamos en disposición de hablar de economías étnicas propiamente dichas. No en vano, en las últimas décadas hemos sido testigos de un considerable salto cuantitativo y cualitativo de las minorías intermediarias y los empresarios de enclave hacia una multiplicación vertical y horizontal de los negocios y hacia mayores cuotas de participación de coétnicos como empleados ${ }^{14}$, con una lógica transnacional en la actividad.

Por otro lado, al igual que en el resto de Europa, donde más dificultades ha encontrado el empresario étnico ha sido en la creación de enclaves económicos étnicos. El motivo han sido las constantes trabas jurídicas y administrativas que ha encontrado, unido al corto espacio de tiempo transcurrido desde la creación de los primeros negocios. Por ello, aunque los negocios que instalan los inmigrantes en las ciudades sirven para cambiar el aspecto externo e interno de las mismas, a la vez que modifica la imagen que se tiene de los emprendedores, son realmente poco significativos desde el punto de vista numérico. Pese a ello, diversos estudios ponen de manifiesto que la población local muestra recelo y desconfianza ante el éxito de estos empresarios $^{15}$. Nuevos retos que motivan la necesidad de seguir profundizando en el estudio de la economía étnica, en especial -y como haremos a continuaciónen torno a las diversas corrientes doctrinales que han tratado de interpretarla y sobre el marco jurídico que la desarrolla, con el objeto de poder conocer y desentrañar sus claves pasadas, presentes y futuras.

\section{UNA APROXIMACIÓN A LAS CORRIENTES DOCTRINALES Y AL MARCO NORMATIVO DEL NEGOCIO ÉTNICO EN ESPAÑA Y EN LA UE}

De esta forma, en los últimos treinta años han proliferado numerosas corrientes doctrinales. Pretenden explicar la creación y el fomento de iniciativas empresariales por parte de los inmigrantes en las sociedades de instalación. Pese al amplio abanico de opciones, se han terminado imponiendo tres

${ }^{14}$ ARJONA, A., Inmigración y mercado de trabajo. El caso de la economía étnica en Almería (Almería: Universidad de Almería, 2004) y Solé, C. y S. PARElla, S., Negocios étnicos. Los comercios de los inmigrantes no comunitarios en Cataluña (Barcelona: CIDOB, 2005).

15 Aramburu, M., Los otros y nosotros (Madrid: Ministerio de Educación, Cultura y Deporte, 2002), 323-356; y Moreras, J., Musulmanes en Barcelona, Espacios y dinámicas comunitarias (Barcelona: CIDOB, 1999). 
grandes líneas teóricas: la aproximación culturalista, la ecológica y la interactiva, procedentes del modelo norteamericano ${ }^{16}$. A ellas se suma la teoría de la «incrustación o encajado mixto», que es la de mayor calado en Europa ${ }^{17}$.

En torno a la doctrina constitucional, el modelo que más nos interesa es el del mixed embeddedness o de «incrustación social». No sólo por ser el imperante, sino el que más enfatiza el contexto de recepción y los marcos jurídiconormativos en el viejo continente, como elementos claves en la formación de emprendedores étnicos. Tiene su origen en los estudios de KLOOSTERMAN y sus colaboradores (1999) y, frente a la postura interactiva - centrada en un excesivo economicismo-, introduce una fórmula de oportunidad que abarca tanto la demanda del consumidor como el régimen normativo ${ }^{18}$. De este modo, frente a doctrinas más idealistas, esta teoría refleja con bastante fidelidad el pragmatismo que ha caracterizado al modelo de Constitución económica imperante en la UE y, por añadidura, en España, donde las economías étnicas dependen de la adecuación entre lo que los grupos pueden ofrecer y lo que les está permitido que ofrezcan ${ }^{19}$. De hecho, su éxito no sólo radica en las redes sociales utilizadas (embeddedness), sino también en la estructura socioeconómica y la política institucional de la sociedad de acogida, donde finalmente se define parte de la estructura de oportunidades de los inmigrantes, más allá de su capital humano.

De hecho, no pocos han sido los ejemplos de buenas prácticas cuya creación y promoción se debe, fundamentalmente, a la permisividad de las autoridades públicas ${ }^{20}$; aun sabiendo de la existencia de prácticas empresariales informales e incluso ilegales (impago de impuestos, ausencia de inscripción en los registros, etc. ${ }^{21}$, como es el caso de algunos negocios étnicos regenta-

${ }^{16}$ Waldinger, R., Ward, R. y H. Aldrich, H., «Trend report. Ethnic business and occupational mobility in advances societies», Sociology 4 (1985), 586-597.

17 Kloosterman, R., Van der Leun, J. y Rath, J., «Mixed embeddedness, (In)formal Economic Activities and Immigrant Businesses in the Netherlands», International Journal of Urban and Regional Research 23, (1999), 252-266; KLOOSTERMAN, R. y RATH, J., «Immigrant entrepreneurs in advanced economies, mixed embeddedness ARJONA Y CHECA, 2006further explored», Journal of Ethnic and Migration Studies 27 (2001), 189201.

18 Citados en Arjona Garrido, A. y Checa Olmos, J.C., cit., 2006, 123.

19 Ibidem.

20 Rath y Kloosterman, cit., 2000.

${ }^{21}$ En opinión de Tienda y Raijman, tanto la economía étnicamente controlada como la economía de propiedad étnica tienen subsectores formales, informales e ilegales. El sector formal está compuesto por empresas que pagan los impuestos y están registradas oficialmente. El sector informal incluye empresas que, produciendo bienes y mercancías legales, lo hace sin pagar impuestos ni tener reconocimiento oficial. El subsector ilegal está formado por empresas que manufacturan o distribuyen productos o mercancías prohibidas, incluye drogas, juego y documentos falsos. Véase TiEndA, M. y RAIJMAN, J., 
dos por inmigrantes turcos en los Países Bajos). Dentro de éste, el propio KLOOSTERMAN (2000) establece una diversidad de modelos. En su base aparece el neoamericano, originario de Estados Unidos, que se extiende a Australia, Irlanda e Inglaterra. Son países con un considerable crecimiento económico y laboral, acompañado (en contrapartida) de bajos salarios, y muy poco control de los gobiernos en la redistribución y provisión de servicios públicos. Este panorama resulta muy atractivo para los inmigrantes a la hora de crear un negocio; hasta el punto que, en algunas ciudades y para algunas minorías étnicas, la ratio de empleo es mayor que entre los propios autóctonos.

En segundo lugar, encontramos el modelo Rhineland, presente en Austria, Alemania, Francia y Luxemburgo. Ampliamente estudiado por HALLER (2004), se caracteriza por su estructura dicotómica (insider/outsider), y sus llamativos contrastes: altos salarios y seguridad laboral, al mismo tiempo que un elevado desempleo. Lo cual, desemboca en un importante control de los flujos migratorios por parte del Estado, y la correspondiente imposición de trabas y obstáculos a la inserción laboral de los inmigrantes.

También es destacable el modelo nórdico, vigente en Dinamarca y Suecia. En consonancia con el anterior, el Estado controla de forma significativa la economía -a través de su red industrial-, y de la regulación de las relaciones laborales y la implementación de las políticas de igualdad; con lo cual, la economía se contrapesa con políticas activas del mercado de trabajo, la expansión del Estado de bienestar y la igualdad de género. Todo ello redunda en la menor proliferación de empresarios étnicos que en los casos anteriores, pues incita a los inmigrantes a insertarse en el mercado de la economía abierta.

En relación al caso español, la doctrina ha realizado importantes esfuerzos para ajustar la realidad social y económica de los emprendedores étnicos al marco europeo. Ello se debe al hecho de que no sólo no contamos con un modelo o referente puro, sino que existen notables divergencias con otros modelos europeos -incluyendo los descritos con anterioridad-, por lo que muchos autores coinciden en equipararlo a los postulados teóricos de la corriente interactiva, alejándolos de los del mixed embeddedness. Si bien, la mayoría lo relacionan con el modelo Rhineland, aunque con significativas variantes. Entre otras: elevada tasa de desempleo en relación con otros Estados centroeuropeos y de Europa del norte, enormes diferencias regionales, altos índices de economía sumergida -por encima del $35 \%$ en sectores como la agricultura, el calzado o el servicio doméstico; o una fuerte subida del

«Immigrants» Income Packaging and Invisible Labor Force Activity», Social Science Quarterly 81 (2000), 291-310; así como BouRGEOIS, I., In search of respect: selling crack in El Barrio (Cambridge: Harvard University Press, 1995), 406. 
empleo temporal y precario -sobre todo en agricultura, construcción, servicios personales y hostelería - frente al empleo estable y bien remunerado. Este es el caso de algunos países del sur de Europa. Entre ellos, España, Italia, Portugal y Grecia. Por todo ello, algunos autores como ARJONA y CHECA se atreven a definir un modelo más acorde a esta realidad, que denominan South-European Model inspirándose en la doctrina anglosajona. Según estos últimos, «en este modelo, los emprendedores étnicos tienen que sortear una enorme cantidad de obstáculos para conseguir el objetivo de instalar un negocio y que éste prospere, por lo que quedan a expensas de decisiones contextuales externas con poco margen a las iniciativas empresariales internas $\rangle^{22}$.

De forma más específica, MORERAS (1999) profundiza en el análisis de las estrategias étnicas. Afirma que estos negocios suelen ser de tipo familiar, horario prolongado, especialización en los productos o ubicación urbana. Además, están especialmente extendidos en la comunidad autónoma catalana, sobre todo en la capital barcelonesa. Por su parte, SOLÉ y PARELLA subrayan que, pese apuntar hacia el modelo norteamericano -en el que la auto-ocupación se erige como una opción atractiva para los inmigrantes más emprendedores-, son muy pocos los que lo consiguen por la rigidez de nuestras políticas socio-laborales, caracterizado por un contexto de recepción y un marco de régimen normativo mucho más estricto ${ }^{23}$. De hecho, quienes sí llevan a cabo su proyecto necesitan como media entre cinco y siete años para conseguirlo, debido a las numerosas trabas burocráticas que encuentran, como ya hemos apuntado. -Por ejemplo, en aquellas ocasiones en las que la Administración del Estado deniega el visado de residencia para trabajar por cuenta propia cuando se trata de una actividad inicial-. Así pues, coincidiendo con ARJONA y CHECA, como regla general podemos afirmar que el emprendedor étnico que pretende establecerse por cuenta propia en nuestro país encuentra más dificultades para hacerlo que si lo hiciera por cuenta ajena (2006, p. 124). El principal motivo es la restrictividad de nuestra legislación a la hora de conceder estos permisos de trabajo, al margen del cumplimiento de la normativa general aplicable al conjunto de los nacionales. Sin ir más lejos, en torno a la suficiencia de la inversión, la incidencia de la actividad a desarrollar, la generación de empleo, la cualificación profesional, la aportación de capital a la economía nacional o incluso de nuevas tecnologías. Pero las restricciones no terminan una vez que el inmigrado consigue todos los permisos y autorizaciones estatales. A partir de ahí, deberá sortear los impedimentos que encontrará en el contexto local. Entre ellos, la concesión de la licencia de apertura por parte del Ayuntamiento, la posible arbitrariedad del

\footnotetext{
22 ARJONA y MORA, cit., 2006, 125.

23 Solé y Parella, cit., 2005, 19.
} 
funcionariado municipal a la hora de evaluar el proyecto $^{24}$, la propia competencia del mercado local o la respuesta -más o menos positiva, o incluso de confrontación- de la sociedad de acogida. En definitiva, en España nos encontramos en pleno proceso de búsqueda de reconstrucción de nuevos modelos de integración económica, jurídica y socio-laboral. $\mathrm{O}$, lo que es lo mismo, de nuevos aportes teóricos que expliquen nuestra realidad, claramente determinada por el contexto de recepción y acotada por un régimen jurídico más estricto que el de otros países europeos.

\section{LA CONSTITUCIÓN ECONÓMICA EN LA ENCRUCIJADA}

Como hemos podido constatar, los estudios relativos al emprendimiento étnico han privilegiado mayoritariamente los aspectos sociales y económicos del fenómeno en detrimento de los aspectos jurídicos. La literatura científica ha preferido centrarse en el perfil del inmigrante como trabajador, considerando la actividad económica como el principal motor para su plena integración en la comunidad de acogida. Por ello, también es oportuno que nos detengamos por un instante y analicemos los posibles modelos de relación existentes entre la Constitución económica y la economía étnica. Fundamentalmente, con el objeto de poner en valor la Constitución económica -en su sentido más puro y formal-, como aquella parte de la Constitución que contiene los derechos que legitiman la actuación de los sujetos económicos, el contenido y límite de estos derechos, la responsabilidad que comporta el ejercicio de la actividad económica; así como las instituciones competentes para establecer la normativa adecuada o las instituciones jurisdiccionales ante las cuales pueden hacerse valer aquellos derechos, reclamar contra su vulneración y hacer efectiva la responsabilidad derivada de un uso obsesivo de aquellos.

De esta forma, si partimos de una premisa histórica, desde la promulgación de la Ley Fundamental de Weimar, en 1919, constatamos que el tema de la Constitución económica se ha convertido asimismo en uno de los tópicos más relevantes y estudiados del Derecho constitucional a nivel nacional, europeo e internacional. No en vano, y coincidiendo con la tesis de DEJUÁN ASENJO, ha llegado a postularse como «una de las encrucijadas de las ciencias sociales con capacidad para polarizar la atención de científicos procedentes de campos tan variados como son el derecho, la politología y la economía $\rangle^{25}$. Pero, como bien señala el autor: no hemos de engañarnos, pues una encrucijada puede llegar a ser tanto un lugar de encuentro, como un lugar

${ }^{24}$ Citado en Arjona Garrido, A. y Checa Olmos, J.C., cit., 124.

${ }^{25}$ Dejuan Asenjo, O., La Constitución económica española (Madrid: CEPC, 1984), 11. 
de paso, -y ello es especialmente evidente en el tema que nos ocupa, a la hora de buscar consensos y respuestas ante los retos que la inmigración está planteando en la actualidad-. Porque, en relación a Europa y España -como Estado miembro de la UE- ha representando mucho más lo segundo que lo primero, generando no sólo desconcierto en los mercados, sino una evidente ambigüedad jurídica. De este modo, ninguna de estas disciplinas ha logrado ponerse de acuerdo entre el «ser» y el «deber ser». Desafortunada y sorprendentemente, tampoco el derecho y sus principales adalides: los juristas, quiénes -con carácter general-han mostrado un relativo desapego por considerarla en ocasiones una «mera recopilación de preceptos programáticos desprovistos de fuerza jurídica». Pero, ¿qué lugar ocupa el fenómeno migratorio en el entramado constitucional económico y en su aplicabilidad directa en España y en la UE, en especial en torno al objetivo de la plena integración del trabajador extranjero?

En el plano europeo, desde la construcción de la Comunidad Europea, la inmigración ha estado presente al constituir una de las cuatro libertades conformadoras del Mercado Común, si bien referida casi en exclusividad a los nacionales de los Estados miembros ${ }^{26}$. Es sobre la base del artículo 39 de Tratado Constitutivo de la Comunidad Europea (TCE) donde se reconoce un conjunto de derechos y libertades a favor del trabajador migrante comunitario, cuyo principio rector era la no discriminación por razón de la nacionali$\mathrm{dad}^{27}$. El objeto principal era evitar cualquier obstáculo para la libre circulación de trabajadores, garantizando su integración y la de sus familiares en el territorio de los Estados miembros ${ }^{28}$.

Posteriormente, durante dos décadas, las instituciones europeas dictaron importantes normas básicas que profundizaban en la idea de libertad de circulación de trabajadores comunitarios ${ }^{29}$, obviando la situación jurídica de los

${ }^{26}$ El actual artículo 26.2 del Tratado de Funcionamiento de la Unión Europea (en adelante TFUE) manifiesta que «El mercado interior implicará un espacio sin fronteras interiores, en el que la libre circulación de mercancías, personas, servicios y capitales estará garantizada de acuerdo con las disposiciones de los Tratados». Véase la versión consolidada del TFUE, [Diario Oficial de la Unión Europea $n .{ }^{\circ}$ C 326, de 26.10.2012].

${ }^{27}$ La versión consolidada del TCE puede ser consultada en el Diario Oficial de la Unión Europea n. ${ }^{\circ}$ C321, de 29.12.2006.

${ }_{28}$ Para profundizar en esta materia, véase el interesante artículo de GORDILLO PÉREZ, L.I. y CANEDo Arrillaga, J.R., «La Constitución económica de la Unión Europea. Bases de un modelo en constante evolución», Cuadernos de Derecho Transnacional Vol. 5/1 (2013): 163-183, en especial p. 165 y ss.; así como Gordillo PÉREZ, L.I., «Constitución, Constitucionalización y Constitucionalismo de la Unión Europea», Estudios de Deusto, Vol. 53/2 (2005), 253-306.

${ }^{29}$ Entre ellas, el Reglamento (CEE) n. ${ }^{\circ}$ 1612/68 del Consejo, de 15 de octubre, relativo a la libre circulación de los trabajadores dentro de la Comunidad [Diario Oficial de la 
nacionales de terceros países ${ }^{30}$. La total eliminación de las fronteras interiores se convirtió en la labor pendiente más urgente, poniendo en el punto de mira a los ciudadanos de terceros Estados. En este contexto se firma el Acuerdo de Schengen, el 14 de junio de 1985, que fue remplazado el 19 de junio de 1990 por el Convenio de Aplicación de Schengen; ambos relativos a la supresión gradual de los controles en las fronteras comunes y que, indudablemente, suponía el primer paso hacia una política común de inmigración. Posteriormente, con la firma del Tratado de Maastricht, el 7 de febrero de 1992, las materias relativas al estatus de los nacionales extracomunitarios mejoraron su posición jurídica, tras ser plasmadas de forma explícita en los textos constitutivos (Título VI del TUE). Pero habrá que esperar hasta la firma del Tratado de Ámsterdam, el 2 de octubre de 1997, para el establecimiento definitivo de la competencia comunitaria en materias de inmigración y asilo. Finalmente, el Tratado de Lisboa (2007) eliminará la estructura de pilares en beneficio de la creación de la UE, cambiando de ubicación la cuestión migratoria, incardinada ahora en el nuevo Título $\mathrm{V}$, denominado «Espacio de libertad, seguridad y justicia», el cual incluye un Capítulo 2 que titula «Políticas sobre controles en las fronteras, asilo e inmigración». Por otro lado, se alude por primera vez de manera expresa a la conformación de una política común de inmigración, acogiendo un nuevo enfoque donde la gestión del fenómeno migratorio adquiere un notable protagonismo y autonomía, dejando de considerarse como una actuación complementaria en el marco de la libre circulación intracomunitaria de personas. Sin embargo, pese a estos avances jurídicos, en el transcurso de 2011, una serie de acontecimientos pusieron en tela de juicio la vigencia del Convenio Schengen. Las

Unión Europea $n .^{\circ}$ L n. $^{\circ}$ 257, de 19.10.1968]; la Directiva 68/360 CEE del Consejo, de 15 de octubre de 1968, sobre supresión de restricciones al desplazamiento y a la estancia de los trabajadores de los Estados miembros y de sus familias dentro de la Comunidad [Diario Oficial de la Unión Europea $n .{ }^{\circ}$ L 257, de 19.10.1968]; o la Directiva 73/148/CEE del Consejo, de 21 de mayo de 1973, relativa a la supresión de las restricciones al desplazamiento y a la estancia, dentro de la Comunidad, de los nacionales de los Estados miembros en materia de establecimiento y prestación de servicios [Diario Oficial de la Unión Europea $n .^{\circ}$ L 172, de 28/06/73].

${ }^{30}$ Ello no es óbice para no reconocer algunos de los avances producidos en la década siguiente. Por ejemplo, la creación del «Grupo de Rodas» a través del Consejo Europeo de Rodas, de 2 y 3 de diciembre de 1988-, encargado de elaborar el informe denominado «Documento de Palma», de junio de 1989, en el que por primera vez se realizaba la distinción entre la vertiente ad intra y ad extra o, lo que es lo mismo, la dimensión interna y externa de la libre circulación de personas. Véase al respecto GARCía JuAN, L., Las medidas de integración de los inmigrantes en la Unión Europea. El modelo competencial y los diferentes enfoques territoriales en el sistema español, Tesis doctoral, dirigida por Ángeles Solanes Corella, Universitat de Valencia, Facultat de Dret, Institut Universitari de Drets Humans, 2014, 27 y ss. 
revoluciones de la «primavera árabe», los conflictos bélicos del norte de África y Oriente Medio, la afluencia masiva de inmigrantes y refugiados especialmente por Italia-, unido a la grave crisis económica que ha venido azotando Europa, ha auspiciado que algunos Estados miembros hayan impuesto graves limitaciones al Convenio, introduciendo controles fronterizos temporales en determinados casos. Ello, junto a las políticas restrictivas, xenófobas y racistas que se han originado o radicalizado en algunos Estados miembros en el plano nacional, han puesto en serio peligro no sólo a una Europa sin fronteras, sino la plena integración del emprendedor étnico en los Estados miembros de la Unión Europea. En especial en aquellos en los que la presión migratoria está siendo más acuciante, como es el caso de Alemania, Austria, Hungría, Serbia, Croacia, Francia o el Reino Unido.

Por su parte, la Constitución española de 1978 no ha podido evadirse de esta disyuntiva a la hora de interpretar y aplicar nuestra Constitución económica. Así, desde su aprobación se han barajado distintas opciones de política económica. Desde 1996, la línea que ha seguido ha sido la reducción del sector público en el seno de una política de privatizaciones, acorde con las tendencias actuales de la Unión Europea ${ }^{31}$. A principios de los noventa se inicia una amplia jurisprudencia del Tribunal de Justicia de la Unión Europea. Siguiendo la estela de sus primeras sentencias, evidencia que determinadas formas de intervención en la vida económica -que parecían amparadas en una interpretación restrictiva del art. 90 TCEE- habían de ceder ante las libertades comunitarias, prevaleciendo la economía de mercado ante las capacidades y competencias de los Estados para organizar su intervención en la vida económica en la forma que mejor garantizaban el Estado de Bienestar ${ }^{32}$.

De este modo, si bien debemos reconocer que nuestra Carta Magna ha mostrado una clara profusión en sus respuestas jurídicas - al mismo tiempo que una creciente preocupación por realidades socioeconómicas y, como no podía ser de otra forma, hacia el fenómeno de la inmigración-, las cláusulas económicas arbitradas y aplicadas han sido generalistas y ambiguas. A ello se ha sumado una clara mediatización política, lo cual ha revertido en su lógico descrédito e inoperancia como norma jurídica (1984, p. 11). En definitiva, pese a que algunos autores han intentado convertirla en parapeto del sistema económico vigente (llámese capitalismo tradicional o socialismo

31 Véanse los artículos 90 y 102 del Tratado de la Comunidad Económica Europea.

32 Véanse las Sentencias del Tribunal de Justicia de las Comunidades Europeas de 19 de marzo de 1991 (Asunto 202/88, República Francesa contra Comisión), de 25 de julio de 1991 (Asunto C-288/89, Caso GOUDA contra COMMISSARIAAT VOOR de Media) y 17 de noviembre de 1992 (Asuntos C-271/90, C-281/90 y C-289/90, Reino de España contra la Comisión). 
democrático) y baluarte frente al poder ejecutivo de turno, muy pocos se han servido de ella como mecanismo de control frente a los abusos de los todopoderosos poderes económicos.

Por ello, ahora más que nunca hemos de poner en valor la potencialidad de los recursos que contiene la Constitución económica española, desde un punto de vista realista y pragmático. Todo ello sin perder de vista los límites con los que lógicamente nos encontraremos, y que podrían desdibujarse tentados por el partidismo político o el tecnicismo aséptico y estéril (1984, p. 12). Necesariamente, deberá partir de una base científica, esencialmente jurídica que, de ningún modo, obvie ni el trasfondo político y social ni una sólida fundamentación económica. Teniendo en cuenta que la norma del artículo $38 \mathrm{CE}$ y la referencia a la libertad de empresa -en el marco de una economía social y de mercado- permiten un sistema económico de economía plenamente liberal, una economía intervenida y/o una economía planificada por lo menos a través de una planificación indicativa. También siendo conscientes, como acertadamente sugiere LASA LÓPEZ, de la necesaria profundización «en la potencialidad de la fórmula y sus posibles efectos, o lo que es lo mismo, en la nueva relación instaurada entre derecho y economía en el Estado pluriclase ${ }^{33}$. De esta forma, se dotaría a la Constitución económica de poderes legítimos, equiparables a los de la Constitución política-, para que ambas puedan erigirse como normas fundamentales para la atribución, organización y control del poder económico. Tarea tan difícil -e incluso utópica-, como necesaria. En especial en el caso que nos ocupa: el análisis del impacto económico, jurídico y socio-laboral del fenómeno del emprendimiento del trabajador extranjero; pues se trata tanto de una razón de justicia social como de seguridad jurídica, que urge de la formalización de una Constitución económica que se ocupe de la atribución y delimitación de los poderes económicos - con auténtica capacidad sancionadora-, y de la defensa de los grupos sociales más necesitados, entre los que encontramos a algunas minorías étnicas. Para ello, como es lógico, será necesario descubrir y estructurar las reglas básicas de la ordenación económica constitucional y su directa repercusión en el fenómeno de la economía étnica.

\section{CONCLUSIONES}

Por todo ello, y a modo de conclusión final, reconocemos la necesidad de que se destaquen los más relevantes preceptos económicos dentro del articulado constitucional. Porque no sólo el ciudadano nacional, sino también el

${ }^{33}$ LASA LÓPez, A., cit., 2 y ss.; teniendo como fuente Mortati, C., «Principi fondamentali (art. 1-12)». Comentario della Costituzione, en BRANCA, G. (a cura di) (Roma: Zanichelli, 1975), 10. 
extranjero, reclama derechos políticos y sociales al mismo tiempo que exige el reconocimiento de sus derechos económicos ${ }^{34}$. Y tanto mejor si es a través de la primera y más elevada norma jurídica: nuestra Constitución. Además, conforme la sociedad y la economía se van haciendo más complejas, los empresarios étnicos siguen reclamando con más fuerza una mayor definición del marco económico. Y lo hacen como sujetos de pleno derecho dado que, a través de su trabajo -y en base a sus posibilidades y necesidades-, participan en el avance y progreso de la propia comunidad que le acoge dentro del ámbito nacional y comunitario, bien sea como ciudadanos o como extranjeros. Porque, en primer lugar, el trabajo constituye un valioso medio de inserción social para las personas extranjeras en las sociedades de acogida. En segundo lugar, porque una vez instalados en él, los emprendedores extranjeros buscan desmarcarse de un modelo étnico, para intentar acceder a una parcela mayor de mercado, extendiéndose a nuevas iniciativas empresariales que incluya a los autóctonos y extranjeros en general. Ello es así porque la lógica de la obtención del máximo beneficio y el mínimo coste se impone a otras razones culturales o propiamente étnicas. En tercer lugar, porque la inclusión del extranjero en la sociedad española y la Europa comunitaria pasa evidentemente por la puesta en marcha de un proceso progresivo de integración social, laboral, económica y cultural, que pueda facilitarle este objetivo primigenio que no obstante estará regulado por las normas jurídicas y de convivencia imperantes en el tejido social y económico de la comunidad de acogida. En cuarto lugar, porque los últimos acontecimientos económicos han impulsado de forma inesperada las actividades empresariales o profesionales autónomas del empresario "étnico», bien como puente para la realización personal del sujeto migrante, bien como medio de vida o para superar una situación laboral dependiente. En quinto lugar, porque los negocios

${ }^{34}$ Por ejemplo, el de la iniciativa privada de los empresarios en el marco de la economía de mercado (artículo $38 \mathrm{CE}$ ), que se conjuga con el derecho de propiedad (artículo $33.1 \mathrm{CE}$ ), teniendo en cuenta que la riqueza del país está subordinada al interés general (artículo 128.1 CE). Por ello, habrán de considerarse ilícitos, entre otros actos, los que impliquen prácticas restrictivas de la competencia y el abuso de la posición dominante en el mercado. También habrá de tenerse en cuenta la función social que la iniciativa económica debe cumplir. El empresario ha de ver compartido su poder de gestión mediante diversas formas de participación de los trabajadores en la empresa. También se ha de facilitar el acceso de los trabajadores a la propiedad de los medios de producción (artículo 129.2 CE). La planificación de la actividad económica fomentará la iniciativa de los particulares para el crecimiento de los recursos del país, tendiendo también a equilibrar y armonizar el desarrollo regional y sectorial (artículos 38 y $131 \mathrm{CE}$ ). Por último, la unidad de mercado exige que las leyes mercantiles tengan carácter estatal (artículo 149-6. ${ }^{\circ} \mathrm{CE}$ ), sin perjuicio de que en algunos aspectos se confíe a la Comunidades Autónomas facultades para su desarrollo y ejecución. 
regentados por personas de origen inmigrante, procedentes de países no comunitarios están transformando el contexto urbano y económico de las ciudades, ocupando una posición crucial en el desarrollo de las pequeñas y medianas economías locales y, por lo tanto, generando nuevas fórmulas de riqueza y prosperidad para Europa y España, y para la constante y necesaria reinvención interpretativa de nuestras Constituciones económicas.

\section{BIBLIOGRAFÍA}

ARamburu, M., Los otros y nosotros (Madrid: Ministerio de Educación, Cultura y Deporte, 2002).

Arjona Garrido, A. y CheCA Olmos, J.C., «Economía étnica. Teorías, conceptos y nuevos avances», en Revista Internacional de Sociología (IRIS) Vol. LXVI/45 (2006): 117-143.

ARJONA GARRIDO, A., Inmigración y mercado de trabajo. El caso de la economía étnica en Almería (Almería: Universidad de Almería, 2004).

Bonacich, E. y Modell, J., The Economic Basis of Ethic Solidarity in the Japanese American Community (Berkeley: University of California Press, 1980).

BonACICH, E., «A theory of ethnic antagonism: The split labor market», American Sociological Review Vol. 37/1-6 (1972): 547-559.

—A Theory of Middleman Minorities», American Sociological Review 38 (1973): 583-594.

BOURGEOIS, I., In search of respect: selling crack in El Barrio (Cambridge: Harvard University Press, 1995).

Dejuan Asenjo, O., La Constitución económica española (Madrid: CEPC, 1984).

GARCÍA JUAN, L., Las medidas de integración de los inmigrantes en la Unión Europea. El modelo competencial y los diferentes enfoques territoriales en el sistema español, Tesis doctoral, Universitat de Valencia, dirigida por Ángeles Solanes Corella, Facultat de Dret, Institut Universitari de Drets Humans, 2014.

Glazer, N. y Moynihan, D.P., Beyond the Melting Pot (Cambridge: MIT Press y Harvard University Press, 1963).

Gordillo Pérez, L.I. y Canedo Arrillaga, J.R., «La Constitución económica de la Unión Europea. Bases de un modelo en constante evolución», Cuadernos de Derecho Transnacional Vol. 5/1 (2013): 163-183.

Gordillo PÉrez, L.I., «Constitución, Constitucionalización y Constitucionalismo de la Unión Europea», Estudios de Deusto Vol. 53/2 (2005): 253-306.

KIM, I. (Edit.), Koreans in the Hood, Conflict with African Americans (Baltimore: Johns Hopkins University Press, 1999).

- «Ethnic enclave economy in urban China: The Korean immigrants in Yanbian», Ethnic and Racial Studies Vol. $26 / 5$ (2003), 802-828.

Kloosterman, R., VAN DeR Leun, J. y Rath, J., «Mixed embeddedness, (In)formal Economic Activities and Immigrant Businesses in the Netherlands», International Journal of Urban and Regional Research 23 (1999): 252-266. 
Kloosterman, R. y RATH, J., «Immigrant entrepreneurs in advanced economies, mixed embeddedness further explored», Journal of Ethnic and Migration Studies 27 (2001): 189-201.

«Outsiders business: A critical review on immigrant entrepreneurship», International Migration Review 34 (2000): 656-680.

LASA LóPez, A., Constitución económica y derecho al trabajo en la Unión Europea (Grandada: Editorial Comares, 2011).

LEE, J., «From civil relations to racial conflict, Merchant-customer interactions in urban America», American Sociological Review 67 (2002): 77-98.

Light, I., «Economías étnicas», Ponencia presentada en el Seminario sobre el Empresariado étnico en España, Centro de Estudios Internacionales e Interculturales, Universidad Autónoma de Barcelona, Barcelona, 2003.

Light, I. y Karageorgis, S., "The ethnic economy», Smelser, N. y Swedenberg, R. (Edits.): The handbook of economic sociology (Nueva York: Russell Sage Foundations, Nueva York, 1994), 647-671.

Logan, J.R., Alba, R.D. y McNulty, T.L., «Ethnic Economies in Metropolitan Regions, Miami and Beyond», Social Forces 72 (1994): 691-724.

Moreras, J., Musulmanes en Barcelona, Espacios y dinámicas comunitarias (Barcelona: CIDOB, 1999).

Olivetti, M., «Articolo 1», en Bifulco, R., Celotto, A. y Olivetti, M. (Coords.), Commentario alla Costituzione Vol. I (art. 1-54) (Torino: Utet, 2006), 5-37.

Solé, C. y S. Parella, S., Negocios étnicos. Los comercios de los inmigrantes no comunitarios en Cataluña (Barcelona: CIDOB, 2005).

TIEndA, M. y RAIJMAN, J., «Immigrants» Income Packaging and Invisible Labor Force Activity», Social Science Quarterly 81 (2000): 291-310.

WAldinger, R., WARD, R. y H. AldRICH, H., «Trend report. Ethnic business and occupational mobility in advances societies», Sociology 4 (1985): 586-597.

Yeung, H. W., "The Internationalization of Ethnic Chinese Business Firms from Southeast Asia, Strategies, Processes and Competitive Advantage», International Journal of Urban and Regional Research 23 (1999): 103-127.

ZноU, M., «Una recapitulación del espíritu empresarial de los grupos étnicos: Convergencias, controversias y avances conceptuales», en Portes, A. y De Wind, J. (Eds.), Repensando las migraciones: Nuevas perspectivas teóricas y empíricas (México: Universidad Autónoma de Zacatecas, 2006), 231-267.

TITLE: "Ethnic economy» as a motor for economic, legal, social and labour integration of immigrant entrepreneurs in Spain and the European Union

RESUMEN: La iniciativa empresarial y económica de las personas extranjeras, a la que nos referiremos como «economía étnica» o ethnic business, constituye un componente de crecimiento muy relevante no sólo para nuestra nación, sino también para el conjunto de países europeos. Emerge como fuente de riqueza económica, puente hacia la movilidad social y el emprendedurismo; así como mecanismo eficaz para la lucha 
contra el estigma social y la trasformación de la imagen negativa y estereotipada en torno a la figura del inmigrante. Partiendo de esta premisa, el presente trabajo pretende mostrar y poner en valor la (hipotética) relación existente entre la Constitución económica, la normativa estatal en materia laboral y la adopción de políticas públicas eficaces, capaces de atraer y consolidar empresas de origen extranjero y con proyección de futuro en España y en la Unión Europea.

PALABRAS CLAVE: Economía étnica, integración, negocio étnico, emprendedor inmigrante.

ABSTRACT: The business and economic initiative of foreigners, which we refer to as "ethnic economy» or "ethnic business», constitutes a very relevant component of growth, not only for our nation but also for all European countries. It emerges as a source of economic growth, bridge towards the social mobility and entrepreneurship; as well as an effective instrument for combating social stigma and the transformation of negative and stereotyped image around the figure of immigrant. Based on this premise, the present paper aims to show and highlight the (hypothetical) relation between the economic constitution, the state labor laws and the adoption of effective public policies, able to attract and consolidate foreign businesses with future forecast in Spain and the European Union.

KEY WORDS: Ethnic economy, Integration, Ethnic business, Immigrant entrepreneurship. 